Journal of Intercultural Studies, 37:2, 95 - 102, (C2016 Taylor \& Francis Group

This is a post-print version (i.e. last manuscript after the peer review process) of the published article; for detailed citations please refer to the original publication, which is available at doi: 10.1080/07256868.2016.1142052.

\title{
End-of-life Care and Rituals in Contexts of Postmigration Diversity in Europe: An Introduction
}

\author{
Alistair Hunter \& Eva Soom Ammann
}

This special issue on migrant dying and death showcases the work of a number of authors exploring a newly emerging field of study within European research and policy contexts. Indeed before the 2000s the question of dying and death in migratory contexts received very little attention from researchers, be it in the social sciences or beyond. At first sight this is puzzling, given that when treated separately these fields have constituted a rich terrain for scholarly inquiry, not least in the discipline of sociology where studies of dying and death (Durkheim 1897) and migration (Thomas and Znaniecki 1918, Park 1928) have been foundational. Even social demographers, who by vocation are attentive to mortality as well as population mobility, seemed reluctant to enter this field of study. In the period before 2000, population health was the only scientific domain in which a substantial body of knowledge accumulated, focussing on the apparent paradox of lower than average mortality rates among migrants in industrialised countries (Markides and Coreil 1986, Abraido-Lanza et al. 1999). Migration scholarship in the social sciences, by contrast, was oriented to younger people, of working age. In following this orientation, migration studies have arguably internalised the priorities of governmental actors and employers, for whom the costs and benefits of migration have long been measured in economic terms (Sayad 2006). This is particularly the case in Europe since the 1960s, which constitutes the geographical and temporal frame of reference for this special issue. As Berger and Mohr's parody of the prevailing logic of European guestworker capitalism put it: 'So far as the economy of the metropolitan country is concerned, migrant workers are immortal [...] they do not age: they do not get tired: they do not die' (Berger and Mohr 1975: 64). 
This short-sighted approach began to lose credibility in the late 1980s, as the first generation of post-WWII labour migrants to Europe began to retire from (or were forced out of) the labour market. The first studies on migrant ageing, focusing on countries which recruited migrants early such as Britain, France and Switzerland, were intended to sound the alarm on the poverty and ill-health which touched the ex-migrant workers, many of whom had worked in physically wearing and poorly paid manual jobs (Samaoli 1989, Blakemore and Boneham 1994, Bolzman et al. 1996). The first studies on death and dying amongst this pioneer migrant generation would follow shortly, with a number of research monographs (Firth 1997, Tan 1998, Chaïb 2000, Gardner 2002) and vanguard contributions in peerreviewed journals (see, for example, Jonker 1996, Reimers 1999, Oliver 2004) appearing around 2000.

It is noteworthy that many of these early studies were written by anthropologists or undertaken from an ethnographic perspective, and that most took as their subject Muslim communities in different European countries. Furthermore, they focused primarily on what happens in migrant communities after a death occurs, rather than describing the preceding transitions involved in dying. The themes which they treated can be summarised under three headings: identities, rituals and legal-institutional aspects. The question of multiple identities and place attachments looms large: many first-generation migrants strived hard to maintain ties with places of origin, yet the experience of settlement in European countries also strongly marked their worldviews (Reimers 1999, Gardner 2002). Funeral rituals are the last opportunity to express such ties of belonging, and these may be complicated in a migration context. Muslims in particular, because of the religious imperatives of whole body burial and uninterrupted repose, have been confronted with a stark choice about where to be interred. The overwhelming preference reported in these early works is for funeral rituals to take place in countries of origin (Chaïb 2000, Gardner 2002), although opting for countries of immigration is interpreted as a practice which would anchor future generations in Europe (Jonker 1996, Reimers 1999, Chaïb 2000). Related to this, a further theme concerns the legal-institutional barriers which arise when relatives, religious specialists and undertakers in countries of residence attempt to faithfully replicate the end-of-life rituals practised in places of origin (Firth 1997, Chaïb 2000, Gardner 2002). Public authorities have erected a rather strict framework of regulations for the treatment and transport of corpses, which sets clear limits to the freedom of organising burial rituals - especially if they stretch over transnational spaces as is often the case for migrants (Zirh 2012).

Legal-institutional barriers may also arise before the funeral, during the different transitions of dying. This is foregrounded in studies of the palliative care provided to dying migrants (see, Spruyt 1999, de Graaff and Francke 2003, Evans et al. 2011, Gunaratnam 2013, Salis Gross et al. 2014). Dying in European late modernity is characterised by a shift from sudden death (for example, from accidents, violence or infection) to slower dying caused by chronic disease and which to a certain degree can be managed and planned by specialist institutions, above all by a highly elaborate medical system with impressive powers to maintain and restore life (Walter 2003, Kellehear 2007, Walter 2012). The manageability of dying, however, also demands that numerous decisions be taken, leading to the construction of the ideal-typical autonomous patient who is expected to be in a position to take prospective decisions and, by doing so, to determine his or her dying. Dying in the context of European 
health services is in this sense dominated by a very specific 'cultural' ideal of self-determined dying. These professional ideals may collide with patients' or relatives' own views of 'good dying': such incompatibilities may arise in many contexts, including but not limited to instances of migrant dying (Gunaratnam 2013).

An additional aspect inherent in the contested notion of 'good death' centres on where death takes place. This has particular significance in migratory contexts: 'good deaths' may be idealised as taking place 'at home' surrounded by loved ones (see for example, Ariès 1981), whereas dying alone or in a foreign or unfamiliar environment may indicate a 'bad death' (Seale 2004). Increasingly however death takes place in institutions of curative or palliative care, where the biomedical aspects of dying can be well-controlled by care professionals, but potentially at a cost to the dignity of the dying person (Kellehear 2007). Producing a 'good death' furthermore involves the appropriate handling of bodies and the social organisation of bereavement rituals after the medically determined moments of death - a dimension often overlooked by public health and health care professionals (Venhorst 2013).

To summarise, a number of contributions about dying and death in migratory contexts have been published in the last 15 years, initially in social anthropology and later in nursing studies. We hesitate however to describe this scientific production as a coherent body of literature because by and large these contributions have not been in dialogue with each other. In part, this can be attributed to language barriers, with an important output in French (see Chaïb 2000, Petit 2002, Aggoun 2006, Lestage 2012) and German (for example, Tan 1998, Salis Gross et al. 2014) remaining largely unknown to Anglophone audiences. Nor has there been much dialogue between European work and research conducted in North America or Australasia, where, in addition to a well-established focus on the challenges of palliative care with ethnically diverse patients (e.g. Turner 2002, McNamara 2004), attention has recently turned to the mounting migrant death toll in increasingly securitised border zones (Nevins 2010, Weber and Pickering 2011).

In reviewing the literature on migrant dying, it is clear that - as in life - no death is the same: differences in cause of death, institutional setting (hospital, hospice or at home), policy contexts (international, national and local) as well as the ethnicity, socioeconomic and residency status of the dying person all lead to manifest heterogeneity. There are, in other words, many angles from which to apprehend dying and death in migratory contexts (Gunaratnam 2013). Without pretending to cover all of them, we do aspire with this special issue to make connections between hitherto closed spheres of inquiry in the hope of generating fresh insights. Furthermore we do so in the expectation that questions around migrant dying will only become more pertinent in Europe in the next decades, as the demographic ageing of migrant communities becomes more prevalent (see, Rallu 2016).

Bringing together seven studies reflecting different institutional and (trans)national contexts of migrant dying, our point of departure is that the end of life is a critical juncture in migration and settlement processes, precipitating novel intercultural negotiations which 
hitherto have not been examined comparatively by scholars. The papers can be broadly categorised under two themes which emerged as central in the above literature review: endof-life care and end-of-life rituals. A key issue when facing death is the organisation of adequate care for the dying, which may be a challenging task in pluralised settings involving both migrant patients and migrant carers. In the next section we introduce the papers devoted to care issues. We then turn to the papers treating ritual aspects: facing the end of life furthermore involves the practice of rituals in order to make sense of the transition from life to death. As regards both care and ritual contexts, the papers show that the need to reconcile different cultural, religious and administrative norms relating to death is infused with ontological insecurities which may result in new or renewed interrogations of identities and belongings, frequently attended by the need to (re-)negotiate frames of reference.

\section{Dying and end-of-life care}

The current state of European research on migrant dying largely treats migrants as a group of patients posing specific challenges to professionals working in institutions of end-of-life care. Migrants' perspectives on dying and end-of-life care, however, have rarely been put centre stage. Research therefore has a tendency to dwell on the specific professional competences needed to deal with migrants' supposedly unique needs.

Critical reflections on professional approaches to migrants' care needs are the starting point for the first contribution of this special issue. Torres, Ågård and Milberg focus on the views and expectations of Swedish end-of-life care providers towards patients with a migrant background. Drawing on data gathered in focus group interviews with end-of-life care professionals, their paper finds that professionals' views on migrant patients are closely linked to expectations of difference and, by extension, expectations of difficulties. Resolving such difficulties requires specific skills (referred to as 'culture competence'), which they do not think they possess. In their analysis, the authors connect the 'othering' concept of 'culture competent care' to the professionally very well-established concept of 'patient centeredness'. They point to the fact that assuming 'otherness' when dealing with migrant patients at the same time implies the assumption of 'sameness' with respect to non-migrant patients. Patient centeredness, in contrary, stresses the uniqueness of every patient, which in itself contradicts the concept of 'sameness'. In recommending that nursing staff focus on individual uniqueness instead of supposed 'otherness', the authors conclude with a conceptual solution to the practical problems perceived by end-of-life care professionals visà-vis patients with migrant backgrounds.

While the first paper focuses on carers, the next contribution by Soom Ammann, Rauber and Salis Gross looks at interactions between carers and dying persons with a migrant background. Based on ethnographic research in Swiss nursing homes focussing on how institutions 'do death', they explore how end-of-life care for migrant elders in long-term care establishments is subject to interpretations by staff of how a 'good death' can be achieved. These interpretations, however, may collide with the interpretations of additional actors involved in 'doing death', such as relatives, but also other professional carers. Caring for 
dying migrants may involve more diversified ideas, and therefore collisions may arise more readily. They are, however, not clearly traceable to 'cultural' systems of reference in the sense of migrant origin, but are more complex. Thus migrant background is, as has already been argued in the first paper, not a decisive line of difference, but an additional frame of reference requiring consideration.

The third paper, by de Graaff, extends the scope of the special issue in two ways. First, it is inclusive of migrant perspectives by foregrounding relatives' views on end-of-life care provision. The paper draws on data from focus groups with the relatives of deceased cancer patients of Turkish and Moroccan background in the Netherlands, as well as interviews with their palliative care professionals. In resonance with the foregoing papers, the article points to challenges stemming from different implicit normative positions. Second, de Graaff is exploring a genuinely new analytic terrain in focusing on the transition between end-of-life care and the 'burial care' involved in preparing the body for the funeral and accompanying the bereaved. The way relatives experience this transition points to a change in their subjectively experienced positionality, which the author traces back to different logics of care. De Graaff argues that palliative care givers, whose worldview is guided by professional standards, can learn from the customer-oriented sensitivity to diverse needs shown by undertakers.

\section{Death and end-of-life rituals}

De Graaff's contribution fruitfully bridges the conceptual gap between end-of-life care and end-of-life rituals and sets the scene for the fourth paper, by Balkan. His focus is the involvement of Muslim undertakers in the intercultural negotiations which are precipitated by the death of Muslims in Berlin, Germany. Drawing on data from interviews and ethnographic research set within Berlin's Islamic funeral and repatriation industry, Balkan pays particular attention to the mediating position which Muslim undertakers have assumed between the German state and Muslim migrant families, mainly of Turkish background. Visà-vis the German state, he finds that undertakers are sometimes called to act as unofficial representatives of their communities in order to allay bureaucrats' misconceptions and prejudice about Muslims. Vis-à-vis Muslim migrant families, the undertakers' mastery of state regulations around burial is a key source of their legitimacy as members of a profession which is otherwise stigmatised due to popular beliefs about profiting from others' misfortune. This mastery also sets them apart from their clients, whom some of the interviewed undertakers berate for their lack of 'integration' and inability to understand the rational-legal order of German society.

The next article, by Milewski and Otto, complements Balkan's fine-grained ethnographic study by maintaining the geographical focus on Muslims in Germany. However, Milewski and Otto add a new dimension insofar as their paper is one of the few in this field to adopt a quantitative socio-demographic approach (see also Attias-Donfut and Wolff 2005). More particularly, their contribution is oriented to the literature on religiosity among migrants and their descendants. While quantitative analyses have been undertaken to test competing 
hypotheses about declines in religiosity due to assimilation or maintenance of religiosity as a means to ethnic identity formation, none have inquired about one key aspect of religiosity, namely religious funerals. Drawing on a sample of 4000 people of Turkish migration background, Milewski and Otto apply logistic regression methods to reveal the significance of different factors in attitudes to religious funerals, such as education, citizenship and partner's origin. They find that the importance of a religious funeral remains high across first and second generations, as well as among those who do not place importance on religion in other phases of the life course.

The sixth paper, by Hunter, continues the discussion initiated by Milewski and Otto regarding the importance of funeral rituals, specifically burial practices. His study, based on qualitative interviews conducted in Britain, Denmark and Sweden, breaks new empirical ground by soliciting the views of Christians of Middle Eastern origin, a migrant group rarely considered by migration scholars working in Europe. Hunter's paper examines how identities are negotiated in and through place by posing the question of preferred burial location. In an ever more mobile world, the ability to develop meaningful identifications with multiple places continues up until the end of life, and for migrants this may present a stark choice: to be buried in the place of origin, the place of residence, a third country or the transnational solution of performing rituals in more than one location. In presenting a typology of motivations for preferred place of burial, supported by examples from his interview data, Hunter shows the multiple, nuanced and sometimes ambivalent relationships between place and identity which are negotiated by Middle Eastern Christians living in Europe.

This theme of multiple and ambivalent belongings in the context of death is taken up in the final paper by Perl. Her analysis reveals an important but easily overlooked point, namely that establishing the identity and belonging of the deceased is a crucial pre-condition of appropriate ritual practice at the end of life. Establishing belonging becomes particularly difficult in the context covered by Perl, namely the deaths at sea of illegalised migrants making the journey from the southern shores of the Mediterranean to Europe. Her article thus extends the empirical scope of the special issue by shining light on a phenomenon which, distressingly and shamefully, has been an all too common occurrence in recent times. Perl goes on to explore the nature of the interactions and power dynamics between the different actors implicated in the identification process - from gravediggers to bureaucrats, police officers, religious institutions and associations of the bereaved - demonstrating how the uncertain belongings of the deceased are produced, suppressed or rewritten. Echoing Balkan's findings about cultural mediation as a means of deflecting the stigma attached to the profession of undertaking, Perl closes her paper by reflecting on the efforts of one Spanish undertaker to identify and repatriate dead border-crossers to Morocco.

By drawing together in this special issue different studies dealing with dying and death in contexts of post-migration diversity in Europe, we hope to initiate a fruitful and more joinedup discussion to take forward this demanding but also very rich field of study. Studying dying and death is in our view not only enriching for migration studies, but also sheds light on dying and death as issues of relevance for humanity as such. The research reported in this issue underlines that migrancy - both as an administrative status and as a biographical set of 
experiences - has the potential to unsettle established norms surrounding dying and death. In this sense, studying dying and death in migratory contexts not only illuminates our understanding of 'the other' but also of 'the self', while at the same time illustrating how diverse lived experiences are as much within 'cultures' as across them. Particularly enriching is the fact that this special issue is not focusing on the moment of death, but is attempting to bridge the issue by looking back at conditions of dying under the dominant 'cultural' ideal of biomedical palliative care and projecting forward to regulations and practices associated with the handling of corpses and the social organisation of bereavement. Intercultural negotiations around dying and death involving migrants in Europe thus shed new light on the structural inequalities which are inherent in the relationship between migrants and powerful institutions of governance.

\section{Acknowledgments}

We are particularly grateful to Marina Richter for her comments on an earlier version of this text.

\section{Disclosure statement}

No potential conflict of interest was reported by the authors.

\section{Notes on contributors}

Dr Alistair Hunter is a British Academy Postdoctoral Fellow at the University of Edinburgh, within the Islamic and Middle Eastern Studies subject area. His current research focuses on ageing and dying in migratory contexts.

Dr Eva Soom Ammann is lecturer and senior researcher in Nursing at the Health Division of Bern University of Applied Sciences. Her research is in the fields of Medical Anthropology, Migration Studies, Public Health and Health Care.

\section{Contact}

Alistair Hunter, alistair.hunter@ed.ac.uk, Islamic and Middle Eastern Studies, 16 George Square, Edinburgh EH8 9LD, UK

\section{References}

Abraido-Lanza, A.F., et al., 1999. The Latino mortality paradox: a test of the "salmon bias" and healthy migrant hypotheses. American journal of public health, 89 (10), 1543-1548.

Aggoun, A., 2006. Les musulmans face à la mort en France. Paris: Vuibert.

Ariès, P., 1981. The hour of our death. London: Allen Lane.

Attias-Donfut, C. and Wolff, F-C., 2005. The preferred burial location of persons born outside France. Population English edition, 60 (5-6), 699-720. 
Berger, J. and Mohr, J., 1975. A seventh man: a book of images and words about the experience of migrant workers in Europe. Harmondsworth: Penguin.

Blakemore, K. and Boneham, M., 1994. Age, race and ethnicity: a comparative approach. Buckingham: Open University Press.

Bolzman, C., Fibbi, R., and Vial, M., 1996. La population âgée immigrée face à la retraite: problème social et problématiques de recherche. In: H.-R. Wicker, J.-L. Alber, C. Bolzman, R. Fibbi, K. Imhof and A. Wimmer, eds. Das Fremde in der Gesellschaft : Migration, Ethnizität und Staat = L'altérité dans la société: migration, ethnicité, état. Zürich: Seismo, 123-142.

Chaïb, Y., 2000. L'émigré et la mort: la mort musulmane en France. Aix-en-Provence: Edisud.

Durkheim, É., 1897. Le Suicide : étude de sociologie. Paris: F. Alcan.

Evans, N., et al., 2011. Appraisal of literature reviews on end-of-life care for minority ethnic groups in the UK and a critical comparison with policy recommendations from the UK end-of-life care strategy. BMC health services research, 11, 141. Available from: http://bmchealthservres.biomedcentral.com/articles/10.1186/1472-6963-11-141.

Firth, S., 1997. Dying, death and bereavement in a British Hindu community. Leuven: Peeters Publishers.

Gardner, K., 2002. Age, narrative and migration: the life course and life histories of Bengali elders in London. Oxford: Berg.

de Graaff, F.M. and Francke, A.L., 2003. Home care for terminally ill Turks and Moroccans and their families in the Netherlands: carers' experiences and factors influencing ease of access and use of services. International journal of nursing studies, 40, 797-805.

Gunaratnam, Y., 2013. Death and the migrant: bodies, borders and care. London: Bloomsbury.

Jonker, G., 1996. The Knife's Edge: Muslim burial in the diaspora. Mortality, 1 (1), 27-43. doi:10.1080/713685827

Kellehear, A., 2007. A social history of dying. Cambridge: Cambridge University Press.

Lestage, F., 2012. Éditorial: La mort en migration. Revue européenne des migrations internationales, 28 (3), 7-12.

Markides, K.S., and Coreil, J., 1986. The health of Hispanics in the southwestern United States: an epidemiologic paradox. Public health reports, 101 (3), 253-265.

McNamara, B., 2004. Good enough death: autonomy and choice in Australian palliative care. Social science and medicine, 58, 929-938.

Nevins, J., 2010. Operation gatekeeper and beyond: the war on 'illegals' and the remaking of the U.S.-Mexico boundary. 2nd ed. New York: Routledge.

Oliver, C., 2004. Cultural influence in migrants' negotiation of death. The case of retired migrants in Spain. Mortality, 9 (3), 235-254.

Park, R.E., 1928. Human migration and the marginal man. American journal of sociology, 33 (6), 881-893. 
Petit, A., 2002. L'ultime retour des gens du fleuve Sénégal : Retours d'en France. Hommes et migrations, 1236, 44-52.

Rallu, J.-L., 2016. Projections of older immigrants in France, 2008-2028. Population, space and place. doi:10.1002/psp.2012

Reimers, E., 1999. Death and identity: graves and funerals as cultural communication. Mortality, 4 (2), 147-166. doi:10.1080/713685976

Seale, C., 2004. Media constructions of dying alone: a form of "bad death". Social science \& medicine, 58 (5), 967-974.

Salis Gross, C., et al., 2014. Chancengleiche palliative care. Bedarf und Bedürfnisse der Migrationsbevölkerung in der Schweiz. Muenchen: AVM.

Samaoli, O., 1989. Un autre regard sur les Maghrébins âgés. Les immigrés vieillissent aussi. Revue hommes et migrations, 1126, 15-24.

Sayad, A., 2006. L'immigration ou Les paradoxes de l'alterité : Tome 1, L'illusion du provisoire. Paris: Raisons d'agir.

Spruyt, O., 1999. Community-based palliative care for Bangladeshi patients in east London. Accounts of bereaved carers. Palliative medicine, 13, 119-129.

Tan, D., 1998. Das fremde Sterben: Sterben, Tod und Trauer unter Migrationsbedingungen. Frankfurt am Main: IKO-Verlag.

Thomas, W.I. and Znaniecki, F., 1918. The Polish peasant in Europe and America: monograph of an immigrant group. Vol. 1. Primary-group organization. Chicago: University of Chicago Press.

Turner, L., 2002. Bioethics and end-of-life care in multi-ethnic settings: cultural diversity in Canada and the USA. Mortality, 7, 285-301.

Venhorst, C., 2013. Muslims ritualising death in the Netherlands: death rites in a small town context. Münster: LIT Verlag.

Walter, T., 2003. Historical and cultural variants on the good death. BMJ British medical journal, 327, 218-220.

Walter, T., 2012. Why different countries manage death differently: a comparative analysis of modern urban societies. The British journal of sociology, 63, 123-145.

Weber, L. and Pickering, S., 2011. Globalization and borders: death at the global frontier. Basingstoke: Palgrave Macmillan.

Zirh, B., 2012. Following the dead beyond the 'nation': a map for transnational Alevi funerary routes from Europe to Turkey. Ethnic and racial studies, 35, 1758-1774. 